\title{
Correction to: Lipid findings from the Diabetes Education to Lower Insulin, Sugars, and Hunger (DELISH) Study
}

Ashley E. Mason ${ }^{1,2^{*}}$, Laura R. Saslow ${ }^{3}$, Patricia J. Moran², Sarah Kim, Priyanka K. Wali², Hiba Abousleiman², Robert Richler ${ }^{2}$, Samantha Schleicher ${ }^{5}$, Veronica M. Goldman², Alison Hartman ${ }^{6}$, Cindy Leung ${ }^{7}$, Wendy Hartogensis ${ }^{2}$ and Frederick M. Hecht ${ }^{2}$

\section{Correction to: Nutr Metab \\ https://doi.org/10.1186/s12986-019-0383-2}

Following publication of the original article [1], the author reported that the co-author's name was missing in the original article.

1. In the correction article the co-author Priyanka K. Wali is added.

\begin{abstract}
Author details
'UCSF Department of Psychiatry, Center for Health and Community, San Francisco, CA, USA. ${ }^{2}$ UCSF Osher Center for Integrative Medicine, 1545 Divisadero Street, Suite 301, San Francisco, CA 94115, USA. ${ }^{3}$ Department of Health Behavioral and Biological Sciences, The University of Michigan, School of Nursing, Ann Arbor, MI, USA. ${ }^{4}$ UCSF Division of Endocrinology, Diabetes and Metabolism, Department of Medicine, San Francisco General Hospital, San Francisco, CA, USA. ${ }^{5}$ University of Maryland, School of Medicine, Annapolis, MD, USA. ${ }^{6}$ Department of Psychology, Drexel University, College of Arts and Sciences, Philadelphia, PA, USA. ${ }^{7}$ Department of Nutritional Sciences, University of Michigan, School of Public Health, Ann Arbor, MI, USA.
\end{abstract}

Published online: 30 December 2019

\section{Reference}

1. Mason, et al. Lipid findings from the Diabetes Education to Lower Insulin,

Sugars, and Hunger (DELISH) Study. Nutr Metab. 2019;16:58. https://doi.org/ 10.1186/s12986-019-0383-2.

* Correspondence: ashley.mason@ucsf.edu

${ }^{1}$ UCSF Department of Psychiatry, Center for Health and Community, San Francisco, CA, USA

${ }^{2}$ UCSF Osher Center for Integrative Medicine, 1545 Divisadero Street, Suite

301, San Francisco, CA 94115, USA

Full list of author information is available at the end of the article

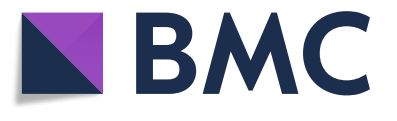

(c) The Author(s). 2019 Open Access This article is distributed under the terms of the Creative Commons Attribution 4.0 International License (http://creativecommons.org/licenses/by/4.0/), which permits unrestricted use, distribution, and reproduction in any medium, provided you give appropriate credit to the original author(s) and the source, provide a link to the Creative Commons license, and indicate if changes were made. The Creative Commons Public Domain Dedication waiver (http://creativecommons.org/publicdomain/zero/1.0/) applies to the data made available in this article, unless otherwise stated. 